\title{
A new golden species of Diasporus (Anura: Eleutherodactylidae) from southwestern Colombia, with evaluation of the phylogenetic significance of morphological characters in Diasporus
}

\author{
Jhon Jairo Ospina Sarria ${ }^{\text {Corresp., } 1}$, David Andrés Velásquez Trujillo ${ }^{1}$, Christian Oswaldo Castaño Saavedra ${ }^{1}$, Luis \\ Fernando Castillo ${ }^{2}$, Wilmar Bolívar-García ${ }^{1,3}$ \\ ${ }^{1}$ Calima, Fundación para la Investigación de la Biodiversidad y Conservación en el Trópico, Cali, Valle del Cauca, Colombia \\ Calidris, Asociación para el Estudio y Conservación de las Aves Acuáticas en Colombia, Cali, Valle del Cauca, Colombia \\ 3 Universidad del Valle, Departamento de Biología, Grupo de Investigación en Ecología Animal, Cai, Valle del Cauca, Colombia \\ Corresponding Author: Jhon Jairo Ospina Sarria \\ Email address: jhon.sarria@fundacioncalima.org
}

A new species of Diasporus is described from the lowlands of southwestern Colombia. The new species, along with Diasporus citrinobapheus, D. gularis, and D. tigrillo are the only species in this genus known to exhibit a yellowish coloration in life. The new species differs from all other congeners in having two chrome orange spots (=glandlike protrusions) on sacral region, smooth ventral skin, basal webbing between the toes, and distal papillae at tips of disc covers on fingers II-IV and toes II-IV. Further, the new species differs from all congeners by an uncorrected $p$-distance of $>5.56 \%$ of the $16 \mathrm{~S}$ rRNA gene fragment examined. In addition to the new species described herein, we demonstrated that the possession of a yellowish coloration in life optimizes unambiguously as a synapomorphy of a clade within Diasporus, which may be recognized as the Diasporus diastema species group. We also discussed the phylogenetic significance of two morphological characters previously considered of systematic value in Diasporus, the occurrence of oval palmar tubercles (undivided) and longitudinal folds (of the vocal sacs) on the throat. On this basis, we demonstrated that these characters appear to be symplesiomorphies rather than synapomorphies of Diasporus. Regarding pointed disc covers (ungual flap) present in some species of Diasporus, we show that this character conflates various characters, involving variation in pad shape, dorsal outline of the disc (ungual flap), and dependence between discs of different digits. Finally, considering that phenotypic data are a valuable source of evidence in testing phylogenetic hypotheses of terraranan frogs, we encourage future research to incorporate phenotypic evidence into phylogenetic studies involved in the genus Diasporus. 


\section{A new golden species of Diasporus (Anura:}

2 Eleutherodactylidae) from southwestern Colombia,

3 with evaluation of the phylogenetic significance of

4 morphological characters in Diasporus

5

6 Jhon Jairo Ospina-Sarria ${ }^{1}$, David Andrés Velásquez-Trujillo ${ }^{1}$, Christian Oswaldo Castaño-

7 Saavedra ${ }^{1}$, Luis Fernando Castillo², Wilmar Bolívar-García ${ }^{1,3}$

8

$9 \quad{ }^{1}$ Calima, Fundación para la Investigación de la Biodiversidad y Conservación en el Trópico, 10 Cali, Colombia

$11{ }^{2}$ Calidris, Asociación para el Estudio y Conservación de las Aves Acuáticas en Colombia.

12 Carrera 24 F Oeste \# 3-25, Cali. Colombia

$13{ }^{3}$ Universidad del Valle, Departamento de Biología, Grupo de Investigación en Ecología Animal

14 A.A. 25360, Cali, Colombia

15

16 Corresponding Author:

17 Jhon Jairo Ospina-Sarria ${ }^{1}$

18 Cali, Valle del Cauca, 760044, Colombia

19 Email address: jhon.sarria@fundacioncalima.org 


\section{A new golden species of Diasporus (Anura: 22 Eleutherodactylidae) from southwestern Colombia,

Jhon Jairo Ospina-Sarria ${ }^{1}$, David Andrés Velásquez-Trujillo ${ }^{1}$, Christian Oswaldo Castaño-

27

28

29

${ }^{1}$ Calima, Fundación para la Investigación de la Biodiversidad y Conservación en el Trópico,

30 Cali, Colombia

${ }^{2}$ Calidris, Asociación para el Estudio y Conservación de las Aves Acuáticas en Colombia. Carrera 24 F Oeste \# 3-25, Cali. Colombia

${ }^{3}$ Universidad del Valle, Departamento de Biología, Grupo de Investigación en Ecología Animal A.A. 25360, Cali, Colombia

Corresponding Author:

37 Jhon Jairo Ospina-Sarria ${ }^{1}$

38 Cali, Valle del Cauca, 760026, Colombia

Email address: jhon.sarria@fundacioncalima.org

40

\section{Abstract}

A new species of Diasporus is described from the lowlands of southwestern Colombia. The new species, along with Diasporus citrinobapheus, D. gularis, and D. tigrillo are the only species in this genus known to exhibit a yellowish coloration in life. The new species differs from all other congeners in having two chrome orange spots (=glandlike protrusions) on sacral region, smooth ventral skin, basal webbing between the toes, and distal papillae at tips of disc covers on fingers II-IV and toes II-IV. Further, the new species differs from all congeners by an uncorrected $p$ distance of $>5.56 \%$ of the $16 \mathrm{~S}$ rRNA gene fragment examined. In addition to the new species described herein, we demonstrated that the possession of a yellowish coloration in life optimizes unambiguously as a synapomorphy of a clade within Diasporus, which may be recognized as the Diasporus diastema species group. We also discussed the phylogenetic significance of two morphological characters previously considered of systematic value in Diasporus, the occurrence of oval palmar tubercles (undivided) and longitudinal folds (of the vocal sacs) on the throat. On this basis, we demonstrated that these characters appear to be symplesiomorphies rather than synapomorphies of Diasporus. Regarding pointed disc covers (ungual flap) present in some species of Diasporus, we show that this character conflates various characters, involving different digits. Finally, considering that phenotypic data are a valuable source of evidence in 
59

60

61

62

63

64

65

66

67

68

69

70

71

72

73

74

75

76

77

78

79

80

81

82

83

84

85

86

87

88

89

90

91

92

93

94

95

96

97

98

testing phylogenetic hypotheses of terraranan frogs, we encourage future research to incorporate phenotypic evidence into phylogenetic studies involved in the genus Diasporus.

\section{Introduction}

The terraranan genus Diasporus (formerly Eleutherodactylus diastema species group sensu Savage, 1997; Lynch \& Duellman, 1997; Lynch, 2001) is presently composed of 16 species, of which three exhibit a yellowish coloration in life-D. citrinobapheus Hertz et al. 2012, D. gularis (Boulenger, 1898), and D. tigrillo (Savage, 1997). In 2011, faunal explorations at the montane forest of the Rio Anchicayá, western slopes of the Cordillera Occidental in the Departamento del Valle del Cauca, Colombia, led us to the discovery of a remarkable golden specimen of genus Diasporus. Morphological examination of this specimen revealed a number of significant morphological differences within the genus (i.e., two chrome orange spots on sacral region, smooth ventral skin, basal webbing between the toes, and disc covers of fingers IIIV and toes II-IV with minute papillae) suggesting that it could be considered a new species. Later, the examination of preserved specimens of Diasporus gularis deposited in the amphibian collection at the Instituto de Ciencias Naturales, Universidad Nacional de Colombia, revealed an additional specimen of this golden species collected by John D. Lynch in the 1990s. More recently, in 2018, field surveys yielded one more specimen. All these three specimens come from localities in the vicinity to the Estación Agroforestal Bajo Calima in the Departamento del Valle del Cauca, Colombia, which is the type locality of another two species of Diasporus-D. quidditus (Lynch, 2001) and D. tinker (Lynch, 2001).

Since the last taxonomic review of Diasporus distributed in northern South America conducted by Lynch (2001), no attempt at a morphological revision has been carried out and no new species have been described from this area. A different trend occurs in Middle America where the proliferation of works dealing with Diasporus has significantly improved our understanding of the systematics and taxonomy of this genus (e.g., Chaves et al., 2009; Hertz et al., 2012; Batista et al., 2016; Garcia-Rodriguez et al., 2016; Arial et al., 2019). Indeed, in Middle America seven species were described in the last nine years (Frost, 2021). But while it is true that this body of knowledge has been favorable for the genus Diasporus, there is still a need to increase the taxon sampling within the genus. In such endeavor, it is necessary to incorporate species distributed in northern South America into future phylogenetic studies involved in overhauling the taxonomy of this genus-Diasporus anthrax (Lynch, 2001), D. gularis, D. quidditus, and $D$. tinker. Moreover, given that there is a degree of taxonomic uncertainty among some Diasporus species (e.g., D. diastema Cope, 1875, D. hylaeformis Cope, 1875, D. quidditus; see Batista et al., 2016; Arias et al., 2019), it is necessary to carry out a taxonomic revision for Diasporus through combined analyses of phenotypic and molecular evidence.

In this paper we describe a new golden species of Diasporus from southwestern Colombia previously confused with $D$. gularis. In addition, we provide molecular data for the new species 
and Diasporus gularis and discussed the phylogenetic significance of two morphological characters previously considered of systematic value in Diasporus, the occurrence of oval palmar tubercles (undivided) and longitudinal folds (of the vocal sacs) on the throat (Cochran \& Goin, 1970, Lynch \& Duellman, 1997; Lynch, 2001). Particularly, our goal with the analysis of phylogenetic significance was to evaluate whether the occurrence of these character states optimize as synapomorphies for Diasporus. Finally, we encourage future research to incorporate phenotypic evidence into the phylogenetic studies involving in the genus Diasporus.

\section{Materials \& Methods \\ Molecular Phylogenetic Analyses}

We conducted phylogenetic analyses based on DNA sequences of two mitochondrial genes (16S, $1270 \mathrm{bp}$ and cytochrome oxidase subunit I - COI, $658 \mathrm{bp}$ ), and one nuclear gene (recombinase activation 1 - RAG-1, 584 bp). Recombinase activation 1 (RAG-1) gene nucleotide sequence was obtained from GenBank. Total genomic DNA was extracted from ethanol-preserved muscle tissue using the DNeasy Tissue Kit Qiagen according to the manufacturer's protocol. PCR amplification was carried out in 30- $\mu \mathrm{l}$ reactions containing 12.5- $\mu \mathrm{l}$ GoTaq Green master mix $2 \mathrm{X}$ (Promega, USA), $0.25-\mu \mathrm{l}$ of each forward and reverse gene primers $(10 \mathrm{mM}), 1-\mu \mathrm{l}$ of extracted DNA, and $16-\mu 1$ of grad water. The mitochondrial genes $16 \mathrm{~S}$ and COI were amplified using the set of primers 16 sar-L/16 sbr-H (Palumbi et al., 1991) and dgLCO-1490/dgHCO-2198 (Meyer, Geller \& Paulay, 2005), respectively. The PCR protocol consisted of an initial denaturation step at $95^{\circ} \mathrm{C}(5 \mathrm{~min}), 32$ cycles consisting of denaturation at $95^{\circ} \mathrm{C}(30 \mathrm{~s})$, annealing at $50^{\circ} \mathrm{C}$ and $48^{\circ} \mathrm{C}$ (30s) for $16 \mathrm{~S}$ and cytochrome oxidase subunit I, respectively, and extension at $72{ }^{\circ} \mathrm{C}(40 \mathrm{~s})$ followed by a final extension step at $72{ }^{\circ} \mathrm{C}(10 \mathrm{~min})$. PCR-products were cleaned using exonuclease plus $1 \mathrm{U}$ of Alkaline Phosphatase per reaction. Purified PCR products were bidirectionally sequenced using a generic analyzer (Macrogen Inc., South Korea). Chromatograms obtained were processed using Sequencher v 5.0.1 (Gene Codes, Ann Arbor, MI, USA). Complete sequences were edited with the software Geneious pro 5.5.7 (Kearse et al., 2012).

For the phylogenetic analyses we included representative sequences of all known and candidate species of Diasporus for which there are available sequences in GenBank (In total, 119 individuals were included in the analysis). Contaminated or misidentified sequences were detected and excluded from our analyses: Diasporus darienensis Batista et al. (2016) (GenBank accession numbers: KT186631 and KT186585) and Diasporus aff. diastema (GenBank accession numbers: KT186633 and KT186588). The sampling outside Diasporus was designed to test hypotheses of monophyly of the genus and character-states polarity of morphological characters. In total, we included sequences of 25 species representing all genera within the family Eleutherodactylidae (Adelophryne Hoogmoed \& Lescure, 1984, Eleutherodactylus Duméril \& Bibron, 1841, and Phyzelaphryne Heyer, 1977) according to the phylogenetic hypotheses of Hedges, Duellman \& Heinicke (2008), Pyron \& Wiens (2011), Padial, Grant \& 
139

140

141

142

143

144

145

146

147

148

149

150

151

152

153

154

155

156

157

158

159

160

161

162

163

164

165

166

167

168

169

170

171

172

173

174

175

176

177

178

Frost (2014), Jetz \& Pyron (2018). Ischnocnema lactea (Miranda-Ribeiro, 1923), a species of Brachycephalidae, was used for rooting the trees. Most DNA sequences were obtained from GenBank, except sequences of the new species and Diasporus gularis (Sequences provided for review in Supplemental Data S1). GenBank accession numbers for the new species, Diasporus gularis, and previously available sequences are provided in the Supplemental Data S2.

Sequences were aligned using the online server of MAFFT software v7 (http://mafft.cbrc.jp/alignment/server/large.html) (Katoh \& Toh, 2008; Katoh, Rozewicki \& Yamada, 2019) under the strategy E-INS-i and default parameters for gap opening and extension. Phylogenetic analyses were performed using Maximum-likelihood and Parsimony inference methods. The maximum-likelihood analysis was performed with IQ-TREE v1.6.12 (Nguyen et al., 2015). ModelFinder was used in IQ-TREE to calculate the best partition schemes and best-fit models of substitution for the data sets (Kalyaanamoorthy et al., 2017). The best partition scheme included four subsets (see Table 1). The maximum likelihood analysis (ML) included 1000 ultrafast bootstrap (UFBoot) replicates (Hoang et al., 2018), with a nearest neighbor interchange search (-bnni) to reduce the risk of overestimating branch support. The parsimony analysis was performed in TNT version 1.5 (Goloboff, Farris \& Nixon, 2008; Goloboff \& Catalano, 2016), using the New Technology Search algorithms. Gaps were considered as a fifth state and transformation events were equally weighted. In addition, we performed a parsimony analysis considering gaps as missing data for comparisons with the maximum likelihood analysis. Parsimony jackknife absolute frequencies were calculated using the New Technology Search algorithms (Goloboff, 1999; Nixon, 1999), as well as requesting 10 hits with driven searches, for a total of 1000 replicates. We favored parsimony (gaps treated as a fifth state) as the optimality criterion because it uses the number of transformations as an optimality criterion to select among heuristic solutions, and propose less costly and easier hypotheses to falsify (Goloboff, 2003; Kluge, 2005; Kluge \& Grant, 2006; Farris, 2008; Grant \& Kluge, 2009). The resulting trees were visualized through the iTOL phylogenetic tree viewer (Letunic \& Bork, 2007) and edited using Inkscape software (XQuartz 2.8.1, http://www.inkscape.org/).

Uncorrected $p$-distances of the $16 \mathrm{~s}$ gene sequences were calculated using the software PAUP v.4.0 (Swofford, 2002) for a dataset with all sequences having the same length and no missing data (575 bp including gaps) and containing only sequences from taxa closely-related to the new species. These sequences were aligned using the software MAFFT under the strategy GINS-i with default parameters for gap opening and extension. Sequences are available in the Dryad Digital Repository (https://datadryad.org/stash/share/knYwth_OJOWi3kh_GlH5BPCIUTEqRydAEuQDVNFkgk).

\section{Morphology}

For morphological analysis, we followed definitions and terminology provided by Lynch \& Duellman (1997) and Lynch (2001) and the standardized format for definitions (diagnoses) 
179 provided by Duellman \& Lehr (2009) for terraranan frogs. Sex was determined by examination 180 of external secondary sexual character (vocal slits) and by direct inspection of gonads. Fingers 181 and toes are numbered pre- to post-axially from I to IV and I to V, respectively. To estimate 182 lengths of toes III and V, we adpressed both toes against Toe IV, and for lengths of fingers I and 183 II, we appressed those fingers against each other. Measurements were taken to $0.1 \mathrm{~mm}$ with dial 184 or digital calipers. Abbreviations are as follows: $\mathrm{SVL}=$ snout-vent length, $\mathrm{HL}=$ head length, 185 IOD = interorbital distance. Institutional abbreviations are: CPZ-UV Colección de Prácticas 186 Zoológicas Universidad del Valle, Cali, Colombia; ICN (Instituto de Ciencias Naturales, Museo 187 de Historia Natural, Universidad Nacional de Colombia, Bogotá), KU (Biodiversity Institute, 188 University of Kansas), and MHUA-A (Museo de Herpetología, Universidad de Antioquia, 189 190 Medellín, Colombia). All specimens examined are listed in the Supplemental Data S3.

\section{Ancestral State Reconstruction}

Among the morphological characters shared by most species of the genus Diasporus, it has been suggested that the occurrence of oval palmar tubercles (undivided) and longitudinal folds (of the vocal sacs) on the throat can have systematic value since they are uncommon in the superfamily Brachycephaloidea (Savage, 1997; Lynch \& Duellman, 1997, Lynch, 2001). On this basis, we defined two characters to describe relevant variation in palmar tubercles and external vocal sacs. In addition to these characters, we also scored the presence of a yellowish coloration in life for all species in our data set. The definitions of the morphological characters and their states are as follows:

Character 0. Palmar tubercle shape: 0 oval, 1 bifid (see fig 3, Lynch 2001).

Character 1. External vocal sacs: 0 not forming folds, 1 forming longitudinal folds (see fig 1, Lynch 2001).

Character 2. Coloration in life: 0 brown to reddish, 1 yellowish (see figs 6-9, Lynch 2001).

The sources of evidence used to score these characters include examination of museum specimens, publications, and field observations. Details on taxonomic distribution for each character and literature sources are listed as Supplemental Data S4. Ancestral character states were reconstructed on the topology obtained with parsimony (gaps treated as a fifth state) under Fitch (1971) optimizations using YBYRÁ (Machado, 2015) and TNT v.1.5 (Goloboff \& Catalano, 2016) to identify and plot synapomorphies. YBYRÁ generates color-coded boxes to indicate if a derived state occurs only in the clade in question (non-homoplastic) or also occurs in other clades (homoplastic) and if it is shared by all terminals of the clade (unique) or is subsequently transformed into one.

Our research was conducted under the authorization of the National Authority of Environmental Licences and the Ministry of Environment and Sustainable Development of Colombia (Resolución 1070 del 28 de Agosto de 2015). The electronic version of this article in Portable Document Format (PDF) will represent a published work according to the International 
219 Commission on Zoological Nomenclature (ICZN), and hence the new names contained in the 220 electronic version are effectively published under that Code from the electronic edition alone.

221 This published work and the nomenclatural acts it contains have been registered in ZooBank, the 222 online registration system for the ICZN. The ZooBank LSIDs (Life Science Identifiers) can be 223 resolved and the associated information viewed through any standard web browser by appending 224 the LSID to the prefix http://zoobank.org/. The LSID for this publication is:

225 urn:lsid:zoobank.org:pub:149A419D-DF15-424F-BB6E-1D41894F1DB4. The online version of 226 this work is archived and available from the following digital repositories: PeerJ, PubMed 227 Central SCIE and CLOCKSS.

228

229

230

231

232

233

234

235

236

237

238

239

240

241

242

243

244

245

246

247

248

249

250

251

252

253

254

255

256

257

258

\section{Results}

\section{Molecular Phylogenetic Analyses}

The phylogenetic analysis using parsimony as optimality criterion (gaps treated as a fifth state) resulted in 30 most-parsimonious trees of 5,879 steps. One of the trees is shown in Figure 1. The conflict between these optimal trees involves relationships among conspecific specimens of all species of Diasporus, except in D. amirae Arias et al. (2019), and D. sapo Batista et al. (2016). According to our molecular phylogeny, which agrees with earlier studies (e.g., Hedges, Duellman \& Heinicke 2008; Padial, Grant \& Frost 2014; Jetz \& Pyron, 2018), Diasporus is the sister clade of Eleutherodactylus and these in turn form a clade that is sister to a clade formed by the genera Adelophryne and Phyzelaphryne (Fig. 1). The topological differences between the parsimony and the ML analyses involve clades with jackknife values below $50 \%$ in the parsimony analyses and ML ultrafast bootstrap support value of $76 \%$, associated with the position of Diasporus vocator (Taylor, 1955) and the clade composed of D. aff. hylaeformis plus two terminals-Diasporus sp. (MHCH 1678 and SMF 97652) (Fig. S1-S2). Considering gaps as a fifth state, the two terminals of Diasporus sp. (MHCH 1678, SMF 97652) were recovered as D. vocator, with $<50 \%$ jackknife support (Fig. 1); a similar position is recovered when gaps are treated as missing data (Fig. S1). On the other hand, we recovered these two specimens as another distinct lineage in ML (Fig. S2, 96\% ultrafast bootstrap support value), as obtained by Arias et al. (2019).

The specimen of the new golden species is recovered as the sister taxon to a clade containing Diasporus gularis, $D$. aff diastema $\mathrm{EPL}, D$. aff diastema $\mathrm{MM}, D$. tigrillo, D. diastema, and $D$. citrinobapheus across all the analyses with low support $(<50 \%$ jackknife support in the parsimony analyses and 56\% ultrafast bootstrap support value in ML; Fig. 1; Fig. S1-S2). The uncorrected $p$-distances showed a relatively high genetic differentiation of the new species compared to other species of Diasporus (5.56-8.72\%; Table 2). On the basis of phylogenetic and phenotypic evidence, below we provide a formal description of the new species.

Diasporus lynchi sp. nov.

LSID urn:1sid:zoobank.org:act:6A8D759A-0094-459A-B92B-36D18A1D037D 
259 LSID urn:1sid:zoobank.org:pub:149A419D-DF15-424F-BB6E-1D41894F1DB4

260 (Figure 2A-B, 3-4)

261 Proposed standard Spanish name. Rana Dorada de Anchicayá

262 Proposed standard English name. Anchicaya's Golden Frog

263

264

265 Holotype.-CPZ-UV 7298 (field no. JJS 065), an adult male obtained by Jhon Jairo Ospina-

266 Sarria on August 4, 2011, at San Marcos, 54 meters elevation, on the Río Tatabro (= tributary of

267 Río Anchicayá, $3^{\circ} 41^{\prime} \mathrm{N}, 76^{\circ} 56^{\prime} \mathrm{W}$; datum = WGS84), Departamento del Valle del Cauca,

268 Colombia.

269 Paratypes.-Two adult males (ICN 13292 and CPZ-UV 05934). ICN 13292 (field no. JDL

270 13541) obtained by John D. Lynch at Campamento Agua Bonita, Estación Agroforestal Bajo

271 Calima, 300 meters elevation ( $3^{\circ} 59^{\prime} \mathrm{N}, 76^{\circ} 46^{\prime} \mathrm{W}$; datum = WGS84), Departamento del Valle del

272 Cauca, Colombia. CPZ-UV 05934 obtained by Eliana Barona on July 12, 2018, at San Cipriano,

273104 meters elevation, on the Río Escalerete (=tributary of Río Dagua, $3^{\circ} 49^{\prime} \mathrm{N}, 76^{\circ} 53^{\prime} \mathrm{W}$; datum = 274 WGS84), Departamento del Valle del Cauca, Colombia.

275 Diagnosis. - Diasporus lynchi is diagnosed by the following combination of characters: (1) skin 276 on dorsum and venter smooth; discoidal fold absent; dorsolateral folds absent; (2) tympanic 277 membrane absent; tympanum annulus visible through skin round, its length $33-40 \%$ of eye 278 length in two males; supratympanic fold poorly defined; (3) snout subacuminate in dorsal view, 279 truncate in profile; canthus rostralis angular, weakly concave; loreal region slightly concave; (4) 280 upper eyelid bearing two or three small tubercles; narrower than IOD (54.1-60\% IOD); cranial 281 crest absent; (5) choanae small, ovoid; partially concealed by palatal shelf of maxillary arch; 282 dentigerous processes of vomers prominent and positioned posterior to level of choanae, 283 triangular in outline, separated medially by a distance equal to the width of the visible 284 dentigerous process, each dentigerous process of vomers bearing four to six teeth; (6) males 285 having vocal slits and large subgular vocal sac (forming longitudinal folds, Fig. 3B, D); nuptial 286 pads absent; testes white; (7) finger I shorter than finger II; discs slightly wider than digits, disc 287 on finger I smaller than that of finger II and this in turn smaller than discs on fingers III and IV; 288 disc cover on finger I unornamented; papillae on digits II, III, and IV; triangular pads on fingers; 289 (8) fingers with lateral fringes; palmar tubercle oval (undivided; Fig. 4A); thenar tubercle oval, 290 equal in size to palmar tubercle; supernumerary tubercles low, restricted to the proximal 291 segments of fingers III and IV; subarticular tubercles low, with rounded base and larger than 292 supernumerary tubercles; (9) ulnar tubercles absent; (10) heel and tarsus lacking tubercles and 293 folds; (11) oval inner metatarsal tubercle, its length four times its width; low, conical outer 294 metatarsal tubercle one-fourth size of inner metatarsal tubercle; supernumerary plantar tubercles 295 absent; subarticular present; (12) toes bearing lateral fringes; webbing basal, I $2^{-}-2^{+}$II $2^{-}-3^{+}$III $2963^{-}-4^{+}$IV $4-2^{1 / 2} \mathrm{~V}$ (Fig. 4B); toe III shorter than toe V; toe III reaching midway between 297 penultimate and distal subarticular tubercle of toe IV; toe $\mathrm{V}$ extending to distal edge of distal 298 subarticular tubercle of toe IV; discs of toes III-V larger than disc of toe II and this in turn larger 
299 than discs on toe I; discs covers on toe I and V unornamented; discs with minute papillae at tips 300 of toes II, III, and IV; triangular pads on toes; (13) in life, dorsal ground color yellow with dark 301 markings, anterior and posterior surfaces of thighs chrome orange. Two chrome orange spots 302 (=glandlike protrusions) on sacral region (Fig. 3A). Canthal, interorbital, and postocular stripes

303 304 305 306 307 308 309 310 311 312 313 314 315 316 317 318 319 320 321

322

323

324

325

326

327

328

329

330

331

332

333

334

335

336

337

338 are poorly defined. Limbs with darks marking and disc covers blackish gray (Fig. 2A). Ventral surfaces of body almost transparent with scattered iridophores, ventral surfaces of hind limbs chrome orange, and vocal sac yellow with diminutive black spots (Fig. 3B). The iris is goldenbronze with a reddish-brown horizontal streak; (14) SVL in three adult males 19.1, 19.5, and $19.7 \mathrm{~mm}$.

Comparisons with congeners.-Diasporus lynchi is distinctive in the genus by having a yellowish coloration in life, two chrome orange spots (=glandlike protrusions) on sacral region, smooth ventral skin, basal webbing between the toes, and disc covers of fingers II-IV and toes II-IV with minute papillae (Fig. 2). By having a yellowish coloration in life, D. lynchi requires comparison with D. citrinobapheus, D. gularis, and D. tigrillo. From all these species, D. lynchi differs by having two chrome orange spots (=glandlike protrusions) on sacral region (Fig. 3A). In $D$. lynchi, basal webbing occurs between toes whereas tips of disc covers on fingers II-IV and toes II-IV have papillae (both character states absent in D. citrinobapheus and D. tigrillo, Hertz et al. 2012; Savage, 1997). D. lynchi and D. gularis share the occurrence of basal webbing between toes and small papillae on Toes II-IV. However, D. lynchi has smooth ventral skin (areolate in D. gularis, Lynch \& Duellman, 1997) and choanae partially concealed by palatal shelf of maxillary arch (choanae not concealed by palatal shelf of maxillary arch in $D$. gularis Lynch \& Duellman, 1997).

Diasporus lynchi can be easily distinguished from the remaining species of the genus Diasporus by having basal webbing between toes (absent in D. amirae, D. anthrax, D. darienensis Batista et al. 2016, D. diastema, D. igneus Batista, Ponce \& Hertz, 2012, D. majeensis Batista et al. 2016, D. pequeno, D. sapo, and D. ventrimaculatus Chaves et al. 2009; Arias et al. 2019, Chaves et al. 2009, Batista et al. 2012, Batista et al. 2016, Lynch, 2001, Lynch \& Duellman, 1997), dentigerous processes of vomers prominent (absent in D. vocator and D. hylaeformis Savage, 2002), and ventral surfaces of body almost transparent with scattered iridophores (venter brown with cream flecks in D. quidditus and gray to dark brown with white blotches in D. tinker; Lynch, 2001).

Description of the holotype. - An adult male with head as broad as body; head width $38.7 \%$ of SVL; HL $34 \%$ of SVL; snout long, subacuminate in dorsal view and truncate in profile; eyenostril distance $64 \%$ of diameter of eye; nostrils protuberant, directed laterally. Canthus rostralis angular, canthal stripe dark; loreal region slightly concave lacking tubercles; lips no flarep; internarial region depressed; top of head flat; upper eyelid bearing two low tubercles, its width $60.0 \%$ of IOD; supratympanic poorly defined, tympanic membrane not evident, tympanic 
339

340

341

342

343

344

345

346

347

348

349

350

351

352

353

354

355

356

357

358

359

360

361

362

363

364

365

366

367

368

369

370

371

372

373

374

375

376

377

378

annulus present, one postrictal tubercle posteroventral to tympanic annulus. Choanae small, nearly round, partially concealed by palatal shelf; dentigerous processes of vomers prominent and posteromedian to choanae, triangular in outline, each process bearing four teeth; tongue much longer than broad, its posterior border not notched, posterior third not adherent to floor of mouth; paired vocal slits present, longitudinal, lateral to base of tongue; external vocal sac forming longitudinal folds (Fig. 3A, D).

Skin on dorsum smooth, skin on belly, throat, and ventral surfaces of the thighs smooth; discoidal fold absent; cloacal sheath short; no tubercles in cloacal region. Ulnar tubercles absent. Thenar tubercle oval, equal in size to palmar tubercle; supernumerary palmar tubercles at base of fingers III and IV; subarticular tubercles round, flattened and larger than supernumerary palmar tubercles; fingers having lateral fringes; relative lengths of fingers I $<$ II $<$ IV $<$ III, papillae on discs on fingers II, III, and IV; nuptial pads absent. Hind limbs moderately robust; when hind limbs flexed perpendicular to axis of body, heels do not overlap; tibia length $33 \%$ of SVL; foot length $28.2 \%$ of SVL; heel and tarsus lacking tubercles and folds; oval inner metatarsal tubercle, its length four times its width; low, conical outer metatarsal tubercle one-fourth size of inner metatarsal tubercle; toes bearing lateral fringes; basal webbing, I $2^{-}-2^{+}$II $2^{-}-3^{+}$III $3^{-}-4^{+}$IV $4^{-}-$ $2^{1 / 2} \mathrm{~V}$; discs with minute papillae at tips of toes II, III, and IV; relative lengths of toes I $<$ II $<$ III $<\mathrm{V}<\mathrm{IV}$; fifth toe much longer than third, toe $\mathrm{V}$ extending to distal edge of distal subarticular tubercle of toe IV, toe III reaching midway between penultimate and distal subarticular tubercle of toe IV. Supernumerary plantar tubercles absent, subarticular tubercles rounded and flattened. In life, dorsal ground color bright yellow with black or brown reticulations, two chrome orange spots (=glandlike protrusions) on sacral region, and black canthal, interorbital, and postocular stripes. Limbs with darks marking and upper surfaces of discs blackish gray. Hind limbs chrome orange. Vocal sac pale yellow with small black spots and belly almost transparent with scattered iridophores. The palmar and plantar surfaces are dark gray with the digit pads pale gray. The iris is golden-bronze with a reddish-brown horizontal streak. In preservative, the bright yellow and orange colors have faded to a dull yellow, but the black reticulations on dorsum, blackish gray on upper surfaces of discs, and dark gray on palmar and plantar surfaces remain (Fig. 3C-D).

Measurements of holotype (mm). - SVL 19.1, tibia length 6.4, foot length 5.4, HL 6.5, head width 7.4, IOD 3.0, internarial distance 2.5, width of upper eyelid 1.5, diameter of eye 2.5 , eyenostril distance 1.6, diameter of tympanum annulus 1 .

Distribution and ecology.-The holotype was found vocalizing in leaf litter along a forested stream in a primary forest at night. The calls sound like a "whistle". The paratypes were also found along stream in primary but thinned forest. Both paratypes were found at distances no greater than $2 \mathrm{~m}$ from the stream. Thus, the species seems to be associated with streams in primary forests. As in other species of Diasporus (e.g., D. gularis and D. tinker), D. lynchi vocalizes from concealed sites (e.g., dried leaf); therefore, a considerable effort is required to 
379

380

381

382

383

384

385

386

387

388

389

390

391

392

393

394

395

396

397

398

399

400

401

402

403

404

405

406

407

408

409

410

411

412

413

414

415

416

417

418

detect each individual. The species occurs at low elevations in the humid tropical regime (54300 meters elevation) in localities in the vicinity to the Estación Agroforestal Bajo Calima, Departamento de Valle del Cauca, Colombia (Fig. 5), which is the locality type of Diasporus quidditus and D. tinker.

Etymology.-The specific name is an noun in the genitive case and is a patronym for John D. Lynch, who first found the species during his explorations of the Bajo Calima, and in recognition of his many contributions to understanding the taxonomy and systematics of the world's most diverse family-group of amphibians (superfamily Brachycephaloidea = Terraranae).

\section{Ancestral state reconstruction}

In the context of the phylogenetic hypothesis favored herein (Fig. 1), we found that none of the character states related to the variation of palmar tubercles and external vocal sac optimize as a synapomorphy for Diasporus. Conversely, we found that the occurrence of a yellowish coloration in life optimizes as synapomorphy of a clade within Diasporus including $D$. aff. diastema EPL, D. aff. diastema MM, D. citrinobapheus, D. diastema, D. gularis, D. lynchi, and D. tigrillo.

\section{Discussion}

Diasporus was recovered as monophyletic and sister clade to Eleutherodactylus, in agreement with earlier reported phylogenies (e.g., Hedges, Duellman \& Heinicke 2008; Pyron \& Wiens, 2011; Padial, Grant \& Frost, 2014; Jetz \& Pyron, 2018). Within Diasporus, most of the recovered clades are poorly supported in the parsimony and ML analyses (Fig. 1, Fig. S1-S2), suggesting that our knowledge about the phylogenetic relationships of Diasporus is still incomplete (Fig. S1-S2). Based on our results and those of previous analyses (e.g., Batista et al., 2016, Arias et al., 2019), a more intensive character and taxon sampling is critical to rigorously test the phylogenetic relationships within this genus.

With the description of the golden Diasporus lynchi, seventeen species are currently recognized in Diasporus. Diasporus gularis and D. lynchi were recovered within a clade in which most species exhibit a yellowish coloration in life (D. citrinobapheus, D. gularis, D. lynchi, and D. tigrillo) with $<50 \%$ jackknife support (Fig. 1). Among the species comprising this clade, the only exception to the yellowish coloration pattern occurs in Diasporus diastema, which according to the original description exhibits a dark brown coloration (Cope, 1875). Regarding this matter, it is important to point out that the description of Diasporus diastema by Cope (1875) was based on specimens collected by John Bransford during the Panama Canal Survey of 1874, and therefore, it is not clear whether the dark brown coloration recorded by Cope (1875) for Diasporus diastema is the coloration in life or in preservative. More recently Batista et al. (2016) reported that Diasporus diastema is composed of three divergent lineages, eastern Panamanian lowlands (EPL), Majé mountain range (MM) and central Panama (CP). 
419 Remarkably, the yellowish coloration in life appears in two of those lineages (EPL and MM, see 420 fig. 15: Batista et al., 2016). Considering that the presence of a yellowish coloration in life 421 optimizes unambiguously as a morphological synapomorphy of a clade within Diasporus 422 comprising of $D$. aff. diastema EPL, D. aff. diastema MM, D. citrinobapheus, D. diastema, D.

423

424

425

426

427

428

429

430

431

432

433

434

435

436

437

438

439

440

441

442

443

444

445

446

447

448

449

450

451

452

453

454

455

456

457

458 gularis, D. lynchi, and D. tigrillo, we propose to recognize this clade as the Diasporus diastema species group.

\section{Phylogenetic significance of oval palmar tubercles (undivided) and longitudinal folds (of the vocal sacs) on the throat in Diasporus}

Our results demonstrated that none of the character states related to the variation of palmar tubercles and external vocal sac optimize as a synapomorphy for Diasporus. Oval palmar tubercles (undivided) also appear in Eleutherodactylus and Adelophryne (see Supplementary

Data S4). In addition to these findings, the occurrence of oval palmar tubercles (undivided) also has been reported in Pzyzelaphryne miriamae (Hoogmoed \& Lescure, 1984). A similar situation was noted for the occurrence of longitudinal folds (of the vocal sacs) on the throat. Current evidence shows that longitudinal folds (of the vocal sacs) on the throat also occur in some species of Eleutherodactylus from Cuba and Hispaniola (e.g., Lynch \& Duellman 1997; Lynch, 2001; Hedges, Duellman \& Heinicke, 2008). Likewise, the occurrence of longitudinal folds (of the vocal sacs) on the throat has been reported in Adelophryne adiastola (Hoogmoed \& Lescure, 1984: fig. 6). Based on these results, the occurrence of oval palmar tubercles (undivided) and longitudinal folds (of the vocal sacs) on the throat could be judged to be tentatively a symplesiomorphy rather than synapomorphy of Diasporus. Future works increasing taxon sampling outside Eleutherodactylidae will further elucidate whether the occurrences of these characters represent synapomorphies of Eleutherodactylidae.

\section{Comments on the pointed disc covers (ungual flap) in Diasporus}

Although Savage (1997) and Lynch (2001) proposed delimiting the morphological variation of the disc covers in four states (i.e., palmate, spadate, lanceolate, and papillate), such a system of codification involves a logical dependency among several independent characters. Particularly, the system of codification proposed by Savage (1997) and Lynch (2001) entails dependence between the morphologies of ungual flap and disc pads, and at the same time, dependence between discs of different digits. Current empirical evidence suggests that ungual flap and disc pads morphologies vary independently, and these in turn vary independently between fingers (Ospina-Sarria \& Grant 2021). Following Ospina-Sarria \& Grant's proposal, future works investigating the variation in morphology of disc covers must explicitly delimit variation in terms of the morphology of the disc pads and the morphology of ungual flap across different fingers (I, II, and III-IV) as independent characters. To our knowledge, pointed disc covers also occur in Adelophryne and Pzyzelaphryne (Hoogmoed \& Lescure, 1984), but until transformational series are objectively delimited, it is not possible to test the phylogenetic significance of morphological variation of digital discs in Diasporus. 


\section{Conclusions}

461

462

463

464

465

466

467

468

469

470

471

472

473

474

475

476

477

478

479

480

481

482

483

484

485

486

487

488

489

490

491

\section{2}

493

494

495

496

497

498

With the description of Diasporus lynchi, 17 species compose the genus Diasporus. Phylogenetic analyses based on molecular evidence indicate that $D$. lynchi is the sister species of a clade containing D. gularis, D. aff. diastema EPL, D. aff. diastema MM, D. tigrillo, D. diastema, and D. citrinobapheus. Furthermore, we found that the possession of a yellowish coloration in life optimizes unambiguously as a morphological synapomorphy for this clade. Although species of genus Diasporus are characterized by having oval palmar tubercles (undivided) and longitudinal folds (of the vocal sacs) on the throat, none of them optimizes unambiguously as synapomorphies of this genus. Another morphological character that has been suggested to characterize the species of Diasporus is the pointed disc covers (ungual flap), however, there is evidence revealing that multiple characters have been conflated under this character.

Frogs of the genus Diasporus, together with the genus Pristimantis, are among the terraranan genera with the greatest taxonomy uncertainty for many of their taxa. This is because, as mentioned earlier, no attempt at morphological revision has been conducted recently. In the specific case of Diasporus, this situation has led to a lack of confidence in the taxonomic identification of numerous DNA sequences deposited in GenBank (e.g., Diasporus diastema, D. hylaeformis, D. quidditus, D. tinker). To address this situation, it is necessary a taxonomic revision incorporating morphological evidence. Besides, and considering that many species of Diasporus are sympatric and syntopic, we recommend being cautious when assigning species identification based on specimens collected near or at the type locality. For example, the Estación Agroforestal Bajo Calima in the Departamento de Valle del Cauca, Colombia is the type locality of Diasporus quidditus and D. tinker, but D. gularis and D. lynchi can also be found. That is, at the Estación Agroforestal Bajo Calima is possible to find four of the five species of the genus Diasporus known from Colombia, except for D. anthrax that is distributed in the Valle of the Magdalena River (Frost, 2021).

Finally, as has been pointed out in the literature, phenotypic data are a valuable source of evidence in testing phylogenetic hypotheses of terraranan frogs. Therefore, we hope our results encourage further research using phenotypic characters into phylogenetic and taxonomic studies involving the genus Diasporus.

\section{Acknowledgements}

We are grateful to J.D. Lynch (ICN), R. Brown, R. Glor, L. Welton, W.E Duellman (KU), and Neftali Camacho (Natural History Museum of Los Angeles County) for loans of specimens, workspace, and the many other courtesies provided on numerous occasions. Also, we thank J.D. Lynch and J.M. Daza (MHUA-A) for providing photos of Diasporus anthrax, D. quidditus, and D. tinker. We especially thank Eliana Barona, who provided data of the paratype from San Cipriano. L. Barrientos generously provided the sequences used for the new species and $D$. 
499 gularis. For their assistance and hospitality, we are grateful to the local communities from

500 Anchicayá and San Cipriano, Valle del Cauca, Colombia.

501

502

503

504

505

506

507

508

509

510

511

512

513

514

515

516

517

518

519

520

521

522

523

524

525

526

527

528

529

530

531

532

533

534

535

536

537

538

\section{References}

Arias E, Chaves G, Salazar S, Salazar-Zúñiga J.A, García-Rodríguez A. 2019. A new species of dink frog, genus Diasporus (Anura: Eleutherodactylidae), from the Caribbean foothills of the Cordillera de Talamanca, Costa Rica. Zootaxa 4609:269-288. DOI:

10.11646/zootaxa.4609.2.4.

Batista A, Ponce M, Hertz A. 2012. A new species of rainfrog of the genus Diasporus (Anura:

Eleutherodactylidae) from Serranía de Tabasará, Panama. Zootaxa 3410:51-60. DOI:

10.11646/zootaxa.3410.1.4.

Batista A, Köhler G, Mebert K, Hertz A, Veselý M. 2016. An integrative approach to reveal speciation and species richness in the genus Diasporus (Amphibia: Anura:

Eleutherodactylidae) in eastern Panama. Zoological Journal of the Linnean Society 178:267311. DOI: 10.1111/zoj.12411.

Boulenger GA. 1898. An account of the reptiles and batrachians collected by Mr. W. F. H.

Rosenberg in Western Ecuador. Proceedings of the Zoological Society of London 1898:107126.

Chaves G, García-Rodríguez A, Mora A, Leal A. 2009. A new species of dink frog (Anura:

Eleutherodactylidae: Diasporus) from Cordillera de Talamanca, Costa Rica. Zootaxa 2088:114. DOI: 10.11646/zootaxa.2088.1.1.

Cochran DM, Goin CJ. 1970. Frogs of Colombia. Bulletin of the United States National Museum 288:1-655. DOI: 10.5479/si.03629236.288.

Cope ED. 1875 "1876". On the Batrachia and Reptilia of Costa Rica. Journal of the Academy of Natural Sciences of Philadelphia 2(8):93-154.

Duellman WE, Lehr E. 2009. Terrestrial-breeding frogs (Strabomantidae) in Peru. Münster, Germany: Nature und Tier Verlag.

Duméril AM \& Bibron G. 1841. Erpétologie Genérale ou Histoire Naturelle Complète des Reptiles. Volume 8. Paris: Librarie Enclyclopedique de Roret.

Farris JS. 2008. Parsimony and explanatory power. Cladistics 24(5):825-847. DOI: 10.1111/j.1096-0031.2008.00214.x.

Fitch WM. 1971. Toward defining the course of evolution: minimum change for a specific tree topology. Systematic Biology 20:406-416. DOI: 10.1093/sysbio/20.4.406.

Frost D. 2021. Amphibian Species of the World: an Online Reference Version 6.1. Available at https://amphibiansoftheworld.amnh.org/index.php. American Museum of Natural History, New York, USA. doi.org/10.5531/db.vz.0001 (access 19 June 2021).

García-Rodríguez A, Arias E, Chaves G. 2016. Multiple lines of evidence support the species status of the poorly known Diasporus tigrillo and the recently described Diasporus citrinobapheus (Anura: Eleutherodactylidae). Neotropical Biodiversity 2(1):59-68. DOI: $10.1080 / 23766808.2016 .1168076$. 
539 Goloboff PA. 1999. Analyzing large data sets in reasonable times: Solutions for composite 540 optima. Cladistics 15:415-428. DOI: 10.1006/clad.1999.0122.

541 Goloboff PA. 2003. Parsimony, likelihood, and simplicity. Cladistics 19(2):91-103. DOI:

542 10.1016/S0748-3007(03)00017-3.

543 Goloboff PA, Farris JS, Nixon K. 2008. TNT, a free program for phylogenetic analysis.

$544 \quad$ Cladistics 24:774-786. DOI: 10.1111/j.1096-0031.2008.00217.x.

545 Goloboff PA, Catalano SA. 2016. TNT version 1.5, including a full implementation of

546 phylogenetic morphometrics. Cladistics 32(3):221-238. DOI: 10.1111/cla.12160.

547 Grant T, Kluge AG. 2009. Perspective: Parsimony, explanatory power, and dynamic homology

548 testing. Systematics and Biodiversity 7(4):357-363. DOI: 10.1017/S147720000999017X.

549 Hedges SB, Duellman WE, Heinicke MP. 2008. New World direct-developing frogs (Anura:

550 Terrarana): molecular phylogeny, classification, biogeography, and conservation. Zootaxa

551 1737:1-182. DOI: 10.11646/ZOOTAXA.1737.1.1.

552 Hertz A, Hauenschild F, Lotzkat S, Köhler G. 2012. A new golden frog species of the genus

553 Diasporus (Amphibia, Eleutherodactylidae) from the Cordillera Central, western Panama.

554 ZooKeys 196:23-46. DOI: 10.3897/zookeys.196.2774.

555 Heyer WR. 1977. Taxonomic notes on frogs from the Madeira and Purus rivers, Brasil. Papéis

$556 \quad$ Avulsos de Zoologia 31:141-162.

557 Hoang DT, Chernomor O, Von Haeseler A, Minh BQ, Vinh LS. 2018. UFBoot2: improving the

558 ultrafast bootstrap approximation. Molecular biology and evolution 35(2):518-522. DOI:

$559 \quad 10.1093 / \mathrm{molbev} / \mathrm{msx} 281$.

560 Hoogmoed MS, Lescure J. 1984. A new genus and two new species of minute leptodactylid

561

562

563

564

565

566

567

568

569

570

571

572

573

574

575

576

577 frogs from northern South America, with comments upon Phyzelaphryne (Amphibia: Anura: Leptodactylidae). Zoologische Mededelingen 58:85-115.

Jetz W, Pyron RA. 2018. The interplay of past diversification and evolutionary isolation with present imperilment across the amphibian tree of life. Nature ecology \& evolution 2(5): 850858. DOI: $10.1038 / \mathrm{s} 41559-018-0515-5$.

Kalyaanamoorthy S, Minh BQ, Wong TK, Von Haeseler A, Jermiin LS. 2017. ModelFinder: fast model selection for accurate phylogenetic estimates. Nature methods 14(6):587-589. DOI: 10.1038/nmeth.4285.

Katoh K, Toh H. 2008. Recent developments in the MAFFT multiple sequence alignment program. Briefing in Bioinformatics 9:276-285. DOI: 10.1093/bib/bbn013.

Katoh K, Rozewicki J, Yamada KD. 2019. MAFFT online service: multiple sequence alignment, interactive sequence choice and visualization. Briefings in bioinformatics 20(4):1160-1166. DOI: $10.1093 / \mathrm{bib} / \mathrm{bbx} 108$.

Kearse M, Moir R, Wilson A, Stones-Havas S, Cheung M, Sturrock S, Buxton S, Cooper A, Markowitz S, Duran C, Thierer T, Ashton B, Meintjes P, Drummond A. 2012. Geneious

578 Basic: an integrated and extendable desktop software platform for the organization and analysis of sequence data. Bioinformatics 28:1647-1649. DOI: 10.1093/bioinformatics/bts199. 
579 Kluge AG. 2005. What is the rationale for 'Ockham's razor' (a.k.a parsimony) in phylogenetic
580 inference. In: Albert V. Parsimony, Phylogeny, and Genomics. Oxford University Press, 15-

580

581

582

583

584

585

586

587

588

589

590

591

592

593

594

595

596

597

598

599

600

601

602

603

604

605

606

607

608

609

610

611

612

613

614

615

616

617

618 42.

Kluge AG, Grant T. 2006. From conviction to anti-superfluity: old and new justifications of parsimony in phylogenetic inference. Cladistics 22(3):276-288. DOI: 10.1111/j.10960031.2006.00100.x.

Letunic I, Bork P. 2007. Interactive Tree Of Life (iTOL): an online tool for phylogenetic tree display and annotation. Bioinformatics 23(1): 127-128. DOI: 10.1093/bioinformatics/btl529.

Lynch JD. 2001. Three new rainfrogs of the Eleutherodactylus diastema group from Colombia and Panama. Revista de la Academia Colombiana de Ciencias Exactas, Físicas y Naturales 25:287-297.

Lynch JD, Duellman WD. 1997. Frogs of the genus Eleutherodactylus in western Ecuador. Systematics, ecology, and biogeography. Special Publication. Natural History Museum, University of Kansas 23:1-236. DOI: 10.5962/bhl.title.7951.

Machado DJ. 2015. YBYRÁ facilitates comparison of large phylogenetic trees. BMC bioinformatics 16(1):1-4. DOI: 10.1186/s12859-015-0642-9.

Meyer CP, Geller JB, Paulay G. 2005. Fine scale endemism on coral reefs: archipelagic differentiation in turbinid gastropods. Evolution 59:113-125. DOI: 10.1111/j.00143820.2005.tb00899.x.

Miranda-Ribeiro A. 1923. Basanitia lactea (Um novo batracchio das collecções do Museu Paulista). Revista do Museu Paulista 13:851-852.

Nguyen LT, Schmidt HA, Von Haeseler A, Minh BQ. 2015. IQ-TREE: a fast and effective stochastic algorithm for estimating maximum-likelihood phylogenies. Molecular biology and evolution 32(1):268-274. DOI: 10.1093/molbev/msu300.

Nixon KC. 1999. The parsimony ratchet, a new method for rapid parsimony analysis. Cladistics 15:407-414. DOI: 10.1111/j.1096-0031.1999.tb00277.x.

Ospina-Sarria JJ, Grant T. 2021. New phenotypic synapomorphies delimit three molecular-based clades of New World direct-developing frogs (Amphibia: Anura: Brachycephaloidea).

Zoological Journal of the Linnean Society. DOI: 10.1093/zoolinnean/zlab071.

Padial JM, Grant T, Frost D. 2014. Molecular systematics of terraranas (Anura:

Brachycephaloidea) with an assessment of the effects of alignment and optimality criteria. Zootaxa 3825:1-132. DOI: 10.11646/zootaxa.3825.1.1.

Palumbi SR, Martin A, Romano S, McMillan WO, Stice L, Grabowski G. 1991. The simple fool's guide to PCR, version 2.0. University of Hawaii, Honolulu.

Pyron RA, Wiens JJ. 2011. A large-scale phylogeny of Amphibia including over 2800 species, and a revised classification of advanced frogs, salamanders, and caecilians. Molecular

Phylogenetics and Evolution 61:543-583. DOI: 10.1016/j.ympev.2011.06.012.

Savage JM. 1997. A new species of rainfrog of the Eleutherodactylus diastema group from the Alta Talamanca region of Costa Rica. Amphibia-Reptilia 18:241-247. DOI:

PeerJ reviewing PDF | (2021:08:64566:1:1:NEW 30 Oct 2021) 
619 Savage JM. 2002. The Amphibians and Reptiles of Costa Rica. Chicago: University of Chicago 620 Press.

621 Swofford DL. 2002. PAUP*. Phylogenetic analysis using parsimony (*and other methods).

622 Sinauer, USA.

623 Taylor EH. 1955. Additions to the known herpetological fauna of Costa Rica with comments on 624 other species. No. II. University of Kansas Science Bulletin 37:499-575. 


\section{Table 1 (on next page)}

Best partition scheme and best-fit models selected by ModelFinder for the IQ-TREE analysis. 


\begin{tabular}{cll}
\hline Subset & \multicolumn{1}{c}{ Data blocks } & \multicolumn{1}{c}{ Model } \\
\hline 1 & Non coding mitochondrial sequences & TIM2+F+I+G4 \\
2 & Coding mitochondrial sequences 1st, 2nd & TN+F+I+G4 \\
3 & Coding mitochondrial sequences 3rd & TIM+F+G4 \\
4 & Coding nuclear sequences 1st, 2nd, 3rd & TVM+F+G4 \\
\hline
\end{tabular}

1 


\section{Table 2 (on next page)}

Percentage of uncorrected p-distances of the 16S gene of Diasporus species most related to $D$. lynchi sp. nov. (in bold) in the phylogenetic analysis. 


\begin{tabular}{lcccccc}
\hline \multicolumn{1}{c}{ Taxon (n) } & 1 & 2 & 3 & 4 & 5 & 6 \\
\hline 1 Diasporus aff diastema MM (1) & 0.00 & & & & & \\
2 Diasporus citrinobapheus (10) & $4.37-5.10$ & 0.00 & & & & \\
3 Diasporus diastema (5) & $5.09-6.06$ & $2.16-4.10$ & 0.00 & & & \\
4 Diasporus gularis (1) & 6.28 & $7.70-8.37$ & $6.98-8.38$ & 0.00 & & \\
5 Diasporus tigrillo (5) & 5.13 & $3.38-4.33$ & $3.84-5.04$ & 7.91 & 0.00 & \\
6 Diasporus lynchi $(\mathbf{1})$ & $\mathbf{6 . 1 0}$ & $\mathbf{5 . 5 6 - 6 . 5 3}$ & $\mathbf{5 . 5 7 - 6 . 2 9}$ & $\mathbf{8 . 7 2}$ & $\mathbf{6 . 3 2}$ & $\mathbf{0 . 0 0}$ \\
\hline
\end{tabular}




\section{Figure 1}

Phylogenetic relationships of Diasporus and outgroups recovered in one of the most parsimonious trees of 5,879 steps from a parsimony analysis in TNT treating gaps as a fifth state.

Black dots indicate nodes that collapse in the strict consensus. Numbers on nodes are Parsimony jackknife absolute frequencies values. Nodes without values indicate value $<50 \%$ of jackknife value and an asterisk indicates a $100 \%$. Character numbers is given beneath square, with primitive-derived characters states inside square (see text and Supplemental Data S4 for character definitions). Color-coding: blue = Transformed, homoplastic. 


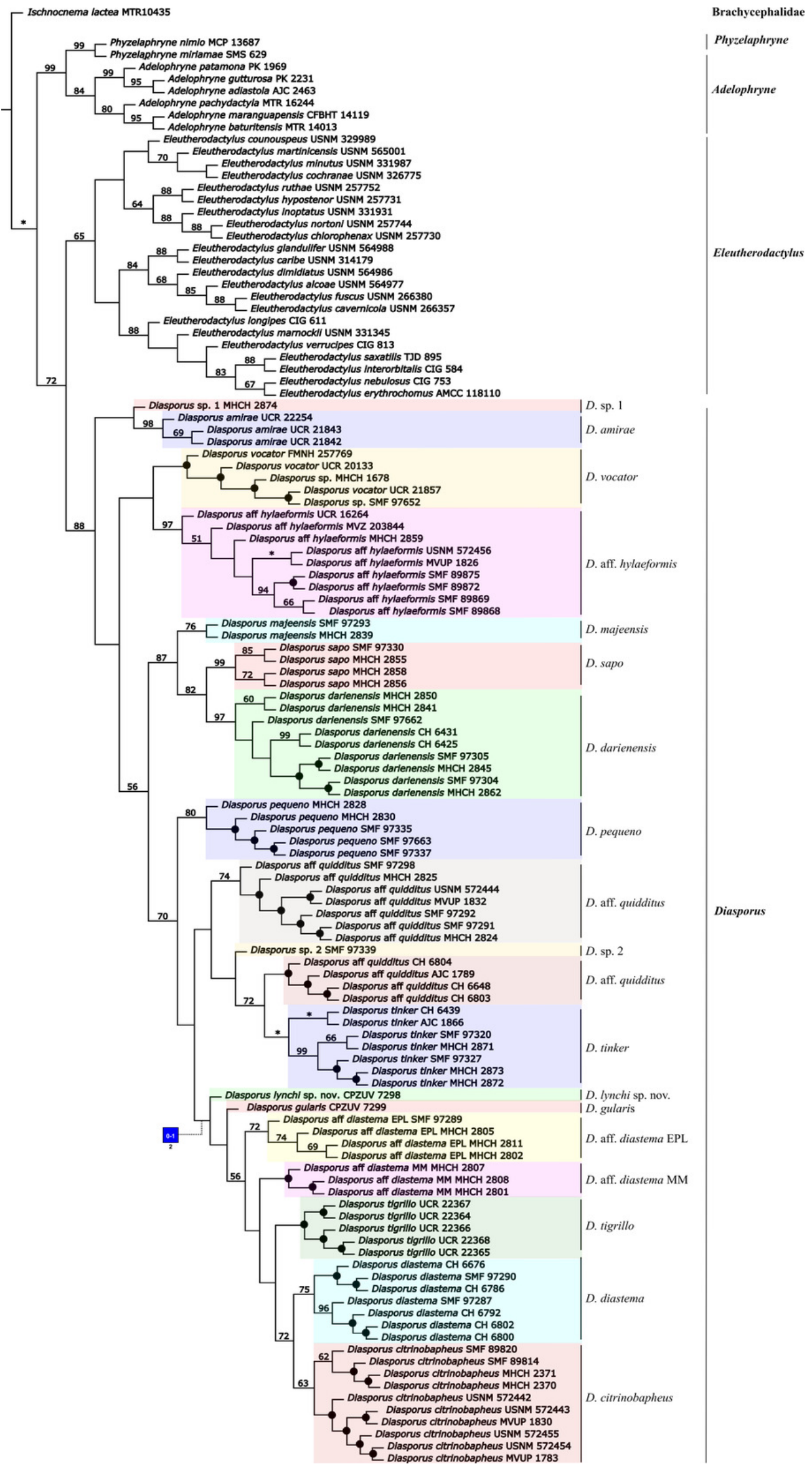




\section{Figure 2}

Living specimens of the Diasporus species known from Colombia.

Diasporus lynchi (A-B; holotype, CPZ-UV 7298 (field no. JJS 065), adult male, snout-vent length [SVL] $19.1 \mathrm{~mm}$; photo: J.J Ospina-Sarria); Diasporus gularis (C; not collected, Pianguita, Valle del Cauca; J.J Ospina-Sarria); Diasporus quidditus (D; holotype, ICN 45173, adult male; photo: J.D. Lynch); Diasporus anthrax (E; MHUAA 09775, San Vicente de Chucuri, Santander; photo: H. Martinez); Diasporus tinker (F; holotype, ICN 45174, adult male; photo: J.D. Lynch). 


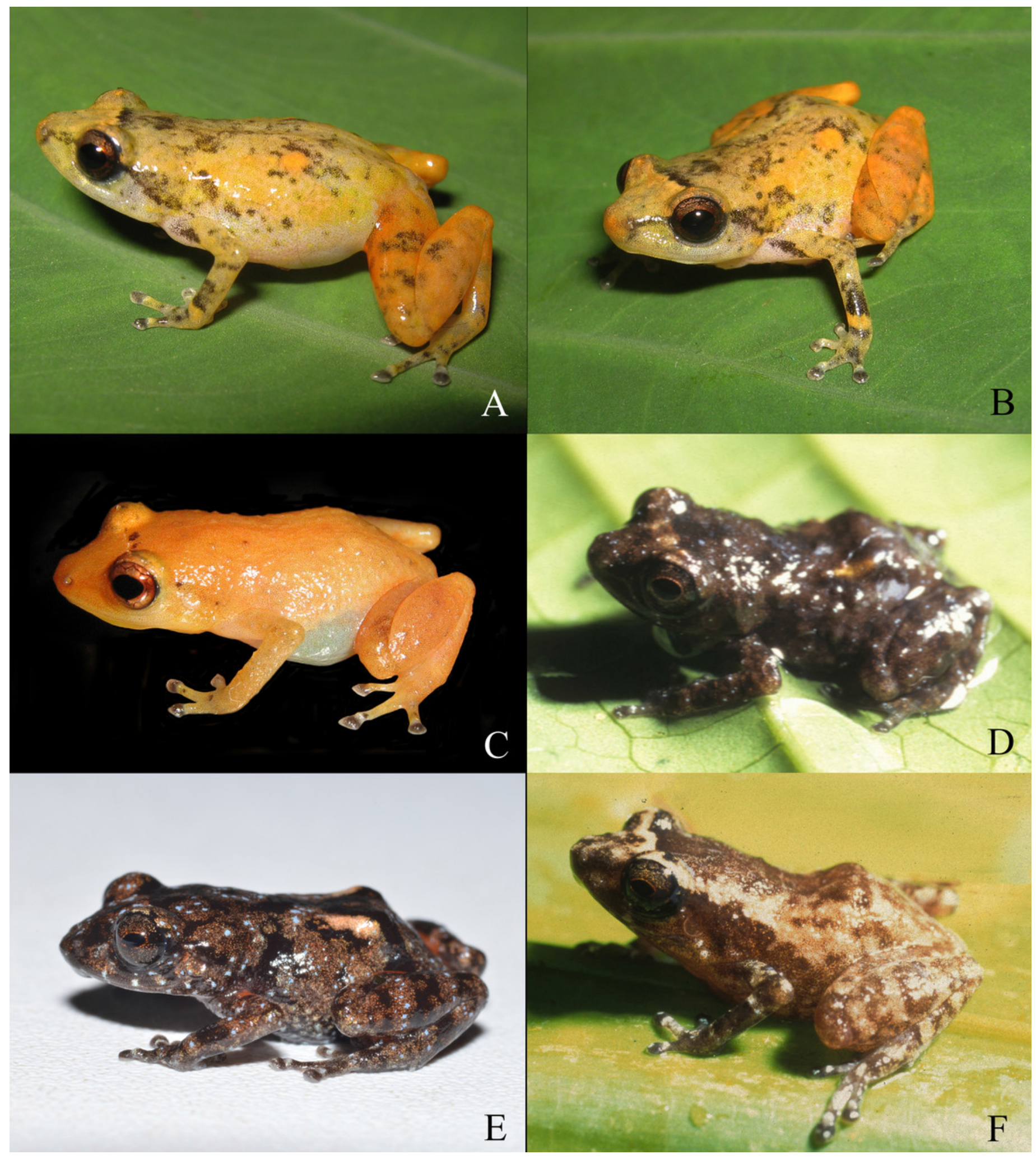


Figure 3

Dorsal and ventral views of Diasporus lynchi (holotype, CPZ-UV 7298 (field no. JJS 065) in life $(A, B)$ and preservative $(C, D)$. Photos: J.J. Ospina-Sarria. 


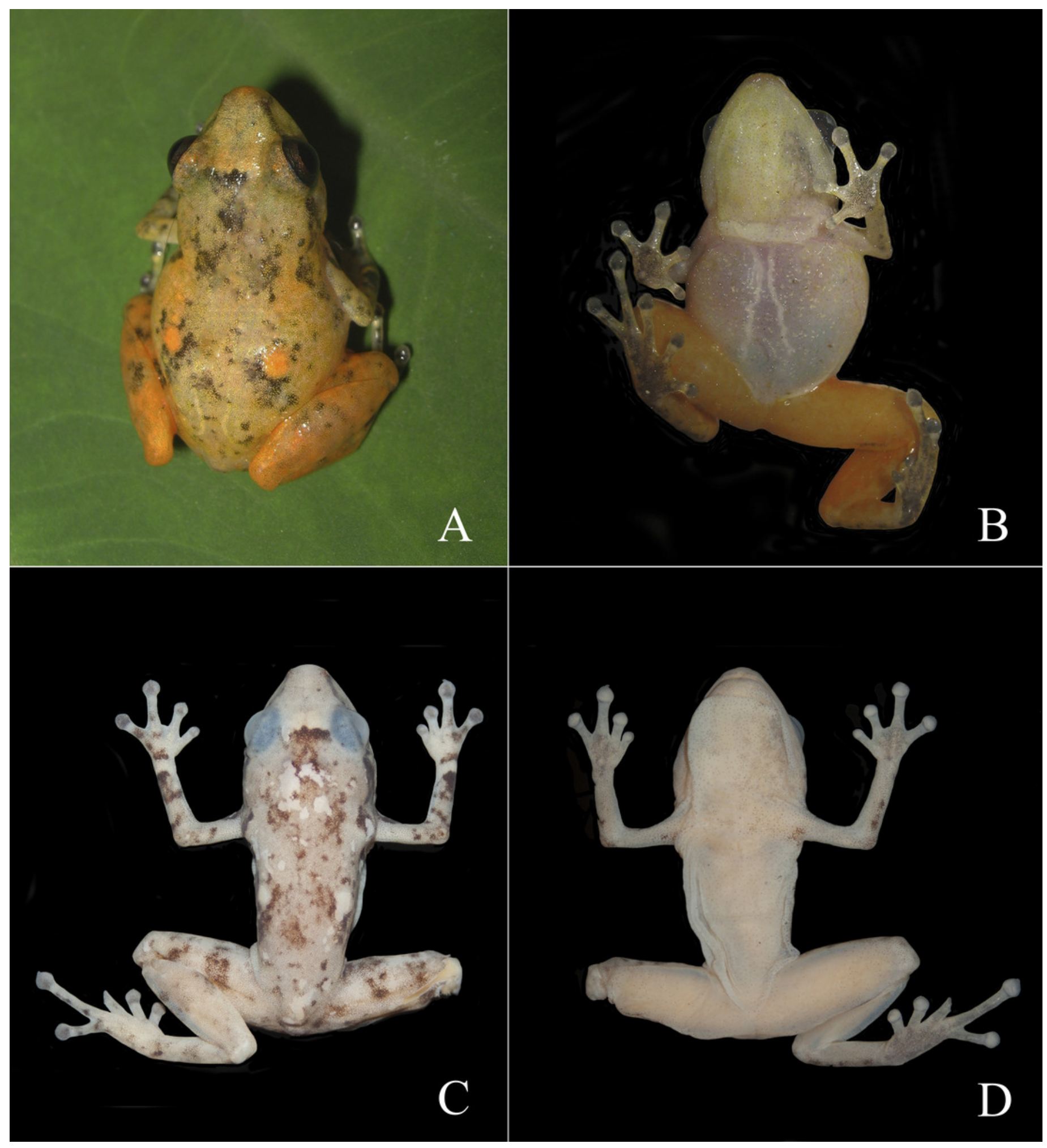




\section{Figure 4}

Ventral view of hand showing lateral fringes on fingers, papillae on digits II, III, and IV, and plantar view of foot showing basal webbing in Diasporus lynchi (A, CPZ-UV 7298, B, CPZ-UV 05934; photos: J.J. Ospina-Sarria). Scale bar $=1 \mathrm{~mm}$.

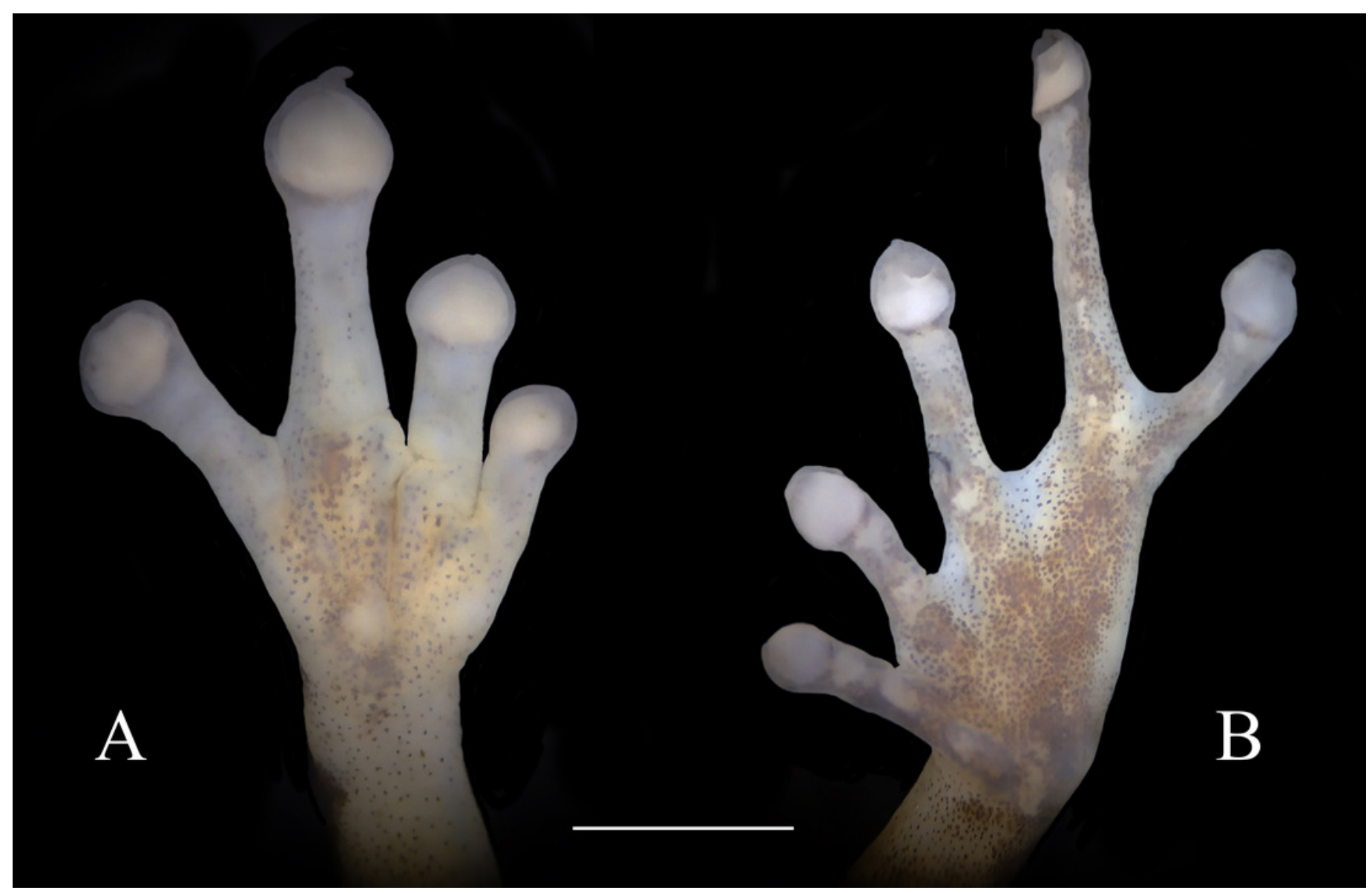


Figure 5

Map of southwestern Colombia (inset) showing localities of Diasporus lynchi: San Marcos (star), San Cipriano (Black circle), and Bajo Calima (white circle). Lines indicate boundaries of department within which the new species is known to occur. 


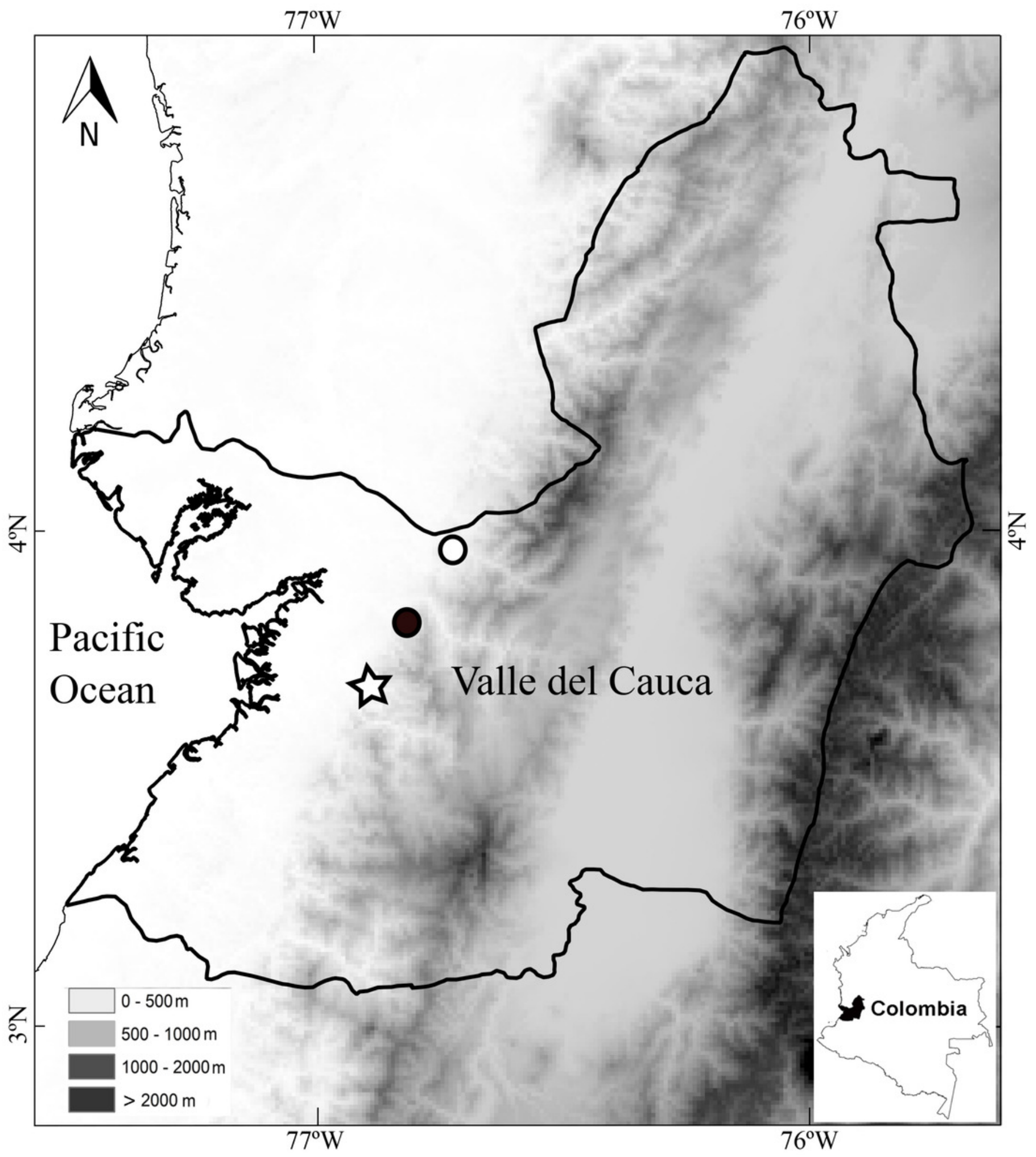

